\title{
Crinoid ancestry without blastozoans
}

Thomas E. Guensburg, Daniel B. Blake, James Sprinkle, and Rich Mooi

Acta Palaeontologica Polonica 61 (2), 2016: 253-266 doi:http://dx.doi.org/10.4202/app.00211.2015

At present, a debate in the paleontologic literature focuses on whether or not the immediate ancestry of the Crinoidea lies in an unidentified member of the Blastozoa, which includes eocrinoids and an assemblage known variously as the "cystoids". Those proposing to derive crinoids from within the blastozoans have recently argued for homologies in the construction of the oral region of certain derived taxa from both groups. An opposing viewpoint, outlined here, finds evidence that aside from plesiomorphies, proposed similarities are superficial and homoplastic. We suggest these superficialities represent convergent adaptive strategies. Earliest crinoids express ambulacral traits unlike any blastozoan but that are expressed in the only other pentaradial echinoderms with a known record early enough to be considered in the context of crinoid origins, edrioasteroids and edrioasteroid-like stem echinoderms.

Key words: Blastozoa, Edrioasteroidea, Crinoidea, origin, homoplasy, Ordovician.

Thomas E. Guensburg [katsuetom@msn.com], Science Division, Rock Valley College, 3301 North Mulford Road, Rockford, Illinois, 61114, USA. Daniel B.

Blake [dblake@illinois.edu], Department of Geology, University of Illinois, 506

West Springfield, Champaign, 61820, USA. James Sprinkle [echino@jsg.utexas.edu

], Department of Geological Sciences, Jackson School of Geosciences, University of Texas, 1 University Station C1100, Austin, Texas, 78712-0254,

USA. Rich Mooi [RMooi@calacademy.org], Department of Invertebrate Zoology and Geology, California Academy of Sciences, 55 Music Concourse Drive, San Francisco, California, 94118-4503, USA.

This is an open-access article distributed under the terms of the Creative Commons Attribution License (for details please see creativecommons.org), which permits unrestricted use, distribution, and reproduction in any medium, provided the original author and source are credited. 
Fof Full text $(1,420.1 \mathrm{kB})$ 